Wójcik Piotr, Rogowska Monika, Chyćko Malgorzata, Tomczyk Jan, Sobstyl Anna, Krasowska Danuta, Kozlowska Marta, Wieteska Malgorzata. Influence of vegetarian diet on human body. Journal of Education, Health and Sport. 2020;10(9):739-746. eISSN 23918306. DOI http://dx.doi.org/10.12775/JEHS.2020.10.09.089

https://apcz.umk.pl/czasopisma/index.php/JEHS/article/view/JEHS.2020.10.09.089

https://zenodo.org/record/4051555

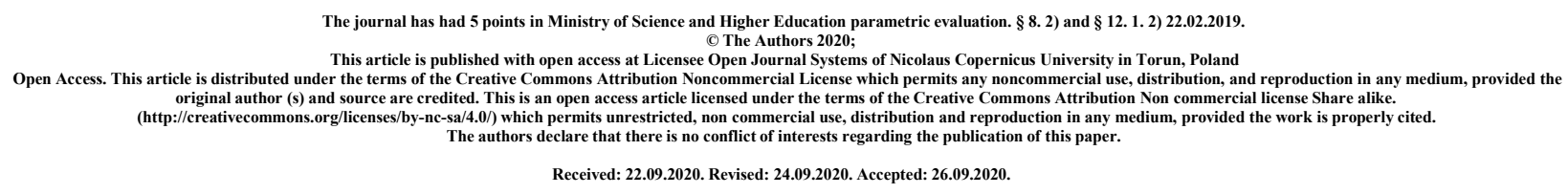

\title{
Influence of vegetarian diet on human body
}

\author{
1 \\ Piotr Wójcik , Monika Rogowska , Małgorzata Chyćko ,
}

1

1

1

Jan Tomczyk , Anna Sobstyl , Danuta Krasowska , Marta Kozłowska , Malgorzata Wieteska

(1) Student Research Circle at the Department of Epidemiology and Clinical Research Methodology, Medical University of Lublin, Poland

(2) Students' Scientific Society at Chair and Department of Public Health

Corresponding author: Piotr Wójcik; piotrek1444@gmail.com

ORCID ID and e-mail:

Piotr Wójcik: https://orcid.org/0000-0002-9078-3701;

piotrek1444@gmail.com

Monika Rogowska: https://orcid.org/0000-0002-9078-3701;

m.rogowska98@gmail.com

Małgorzata Chyćko: https://orcid.org/0000-0002-1515-6038;

malgorzatachycko@gmail.com

Jan Tomczyk: https://orcid.org/0000-0003-1034-3819;

jantomczyk8@gmail.com

Anna Sobstyl: https://orcid.org/0000-0003-0330-574266ty;

sobstyl.anna@onet.pl 
Małgorzata Wieteska: https://orcid.org/0000-0002-1566-7559; malgosia.wieteska@onet.eu

Danuta Krasowska: https://orcid.org/0000-0002-3015-1120, dana.krasowska@gmail.com

Marta Kozłowska: https://orcid.org/0000-0001-7791-508X, m.kozlowska.med@gmail.com

\section{Abstract}

All over the world there are more vegetarians than in previous years due to many reasons. One of them is positive influence on health what is shown in the latest research. The aim of the article is to review the influence of vegetarian diet on frequent diseases such as: hypertension, obesity, osteoporosis.

An analysis of scientific papers from Pubmed and Google Scholar was performed, which most accurately described the issue of impact vegetarian diet on human health. The following keywords have been used in the search: Vegetarian, hypertension, obesity, osteoporosis: vegetarian, hypertension, obesity, osteoporosis.

The researchers shown than vegetarians have lover systolic blood pressure and diastolic blood pressure by 10 and $5 \mathrm{~mm} \mathrm{Hg}$, they also lower overall mortality by $10-15 \%$, risk of heart failure and by $\sim 40 \%$, stroke by $35 \%$ and coronary events by $20 \%$.

Vegetarians also have statistically lower body mass index. What's more in this diet is more energy efficient thanks too low food energy density and helps keeping leptin on adequate level.

Research has shown than vegetarians have lower mineral bone density than non-vegetarian, although some studies has shown that risk of fractures in vegetarians and non-vegetarians was not affected by diet alternation.

Based on the results of the studies above vegetarian diet contributes to lower blood pressure and preventing from cardiovascular diseases. It helps to avoid obesity and to get rid of weights also doesn't have negative impact on osteoporosis.
Key
words:
Vegetarian,
hypertension,
obesity,
osteoporosis

\section{Introduction and purpose}

Vegetarian diet is increasingly popular diet, approximately 375 million of people vegetarian what is estimated as 8 per cent of world's population [1].This diet mainly consists of plant-based foot but also includes animal-derived food such as: honey, eggs, milk, and dairy products. It also characterized by abstention from consuming meat including fishes and seafood [2]. The popularity of plant-based diet has increased over the years from $1 \%$ in 2000 up to about $4 \%$ nowadays just in Poland. Transition to plant-based diet is caused by various factor such as economic, religious, cultural, ethical and ecological. Although increasingly more people choose this type of diet due to its beneficial impact on human health. Despite many health benefits that vegetarian diet has shown in many studies vegetarian diet could have also negative consequences, that's why it needs to be balanced correctly to provide all necessary elements to protect body 
from deficiencies [3]. Recently especially studies have been made to research hypertension, obesity and osteoporosis which are a few of civilization diseases.

The aim of this article was to review effects of vegetarian diet on these health disorders. The information used in this review were obtained from searching database of: Google Scholar and PubMed. The strategy of searching is based on the following keywords: vegetarian, hypertension, obesity, osteoporosis. Articles have been selected in terms of the thematic connection with this article and their content value.

\section{Description of the state of knowledge2.1 Hypertension and vegetarian diet}

Hypertension, according to the European Society of Cardiology is defined as systolic blood pressure higher or equal to $140 \mathrm{mmHg}$ and/or diastolic blood pressure higher or equal to $90 \mathrm{mmHg}$ [4]. Hypertension is a major health problem around the globe. It affects about $25 \%$ of people globally $[5,6,7]$. Worldwide it is the leading cause of death and disability, reaching an approximated $18 \%$ of all deaths $(9.4$ million) $[7,8]$. Fiftythree percent of ischemic heart disease disability-adjusted life-years can be attributed to hypertension [8]. Moreover, hypertension is a risk factor of much life threatening diseases such as ischemic heart disease, ischemic and hemorrhagic stroke, atrial fibrillation or aortic aneurysm. Also, it is the most common comorbidity of chronic kidney disease, both as a cause and an effect of this disorder $[9,10]$.

Given the issues that emerge in relation to hypertension, it is necessary to treat it effectively. For most patients, that means medication-based treatment, aimed to lower blood pressure to an acceptable level. Numerous studies have shown a strong benefit from reducing blood pressure in hypertensive patients. Systolic blood pressure (SBP) and diastolic blood pressure (DBP) lower by $10 \mathrm{mmHg}$ and $5 \mathrm{mmHg}$ respectively, brings down overall mortality by about $10-15 \%$, risk of heart failure by 40\%, stroke by $\sim 35 \%$, and coronary events by 20\% [11, 12]. Interestingly, similar benefits arise from adjusting a patient diet. According to the World Hypertension League, approximately $50 \%$ of hypertension can be linked to patients unhealthy eating habits, out of those almost half (40\%) is diet low in fruits and vegetables [7]. Following that trend, several studies have been conducted that investigate the effects of vegetarian diet on hypertension.

Vegetarian diet is not a very well-defined term, incorporating generally all plant-based diets, including: lacto-ovo-vegetarian diet (LOV), where mostly plant food is eaten, but dairy products and eggs are also included; pesco-vegetarian diet (PV), which allows the consumption of fish and other seafood; some combinations of the two and finally vegan diet (VG), composed solely of plants, excluding all animal products. People on vegetarian diets have statistically lower body mass index (BMI), obesity rate is generally lower among vegetarian communities $[13,14,15,16]$. Obesity is linked to a higher level of oxidative stress and reactive oxygen species [17,18], which are important factors in the pathophysiology of hypertension $[19,20]$. Another factor in the development of hypertension in obesity is insulin resistance, which often accompanies high BMI and is strongly linked to elevated blood pressure [21]. Vegetarian diet includes more dietary fiber, which is also connected to a lower blood pressure [24]. Furthermore, vegetarian diet improves blood viscosity and vasodilation, alters baroreceptors, regulates renin- angiotensin and the sympathetic nervous system, has anti-oxidant and anti-inflammatory properties, adjusts the gut microbiota $[23,24]$. All of these factors work together in reducing the risk of hypertension in vegetarians.

The effect of vegetarian diets on hypertension have been analyzed by several studies in various scenarios. Randomized controlled trials, where individuals were assigned either to a control group, eating a standard omnivorous western diet or on a vegetarian diet, have shown a significant decrease in blood pressure, both in normotensive and hypertensive subjects [25,26,27,28]. Similar trends are observed in observational studies, linking diets with low meat intake to a lower value of blood pressure $[16,29,30]$. These beneficial effects are observed across all subtypes of vegetarian diets, but are stronger in vegans than in LOV or PV. A conclusion can be drawn from mentioned results that changing dietary habits to vegetarian or plantbased can be beneficial for blood pressure and in turn can reduce the amount or dose of drugs taken by a hypertensive patient, which limits risk of adverse effects of these medications.

\subsection{Plant-based diet vs. obesity}


The dynamically growing number of obese people over the years is a 21 st century epidemic and a serious health problem in developed and developing countries [31]. According to data from 2016, the obesity problem affected approximately $11 \%$ of adult men and $15 \%$ of adult women globally [32]. Obesity is a significant risk factor for diseases such as all major gastrointestinal cancers, cardiovascular diseases and type 2 diabetes [33,34]. In the struggle against the extra kilogram, more and more people are taking a vegetarian diet. Interest in the plant-based diet and its potential positive health outcomes is constantly growing [35]. Some studies published so far even focus on the health-promoting effects of the plant-based diet on specific social groups such as the Blacks in the United States [36]. The availability of vegan or vegetarian products is increasing, making it easier to give up meat and animal products. Although the reasons why more and more people choose vegetarianism or veganism are different, one of them is the desire for effective weight loss.

In the fight against obesity it is important to keep your appetite at an appropriate level. A high fiber content in the plant-based diet could have a beneficial effect on gut hormonal-driven appetite regulation and regulation of digestion rate [35].

Additionally, plant-based diet has a beneficial effect on energy metabolism and leptin level in blood. Leptin is a peptide hormone that affects the regulation of appetite and has an important role in controlling body weight. The results of a study involving omnivores, lacto-ovo-vegetarians, and vegans showed that a plant-based diet reduces circulating leptin and body fat storage [37].

The results of the available studies are consistent - a well-balanced vegetarian diet is conducive to weight loss, and in some works it is even listed as one of the most effective methods in the fight against overweight and obesity $[38,39,40]$. The beneficial effect of a plant-based diet on increasing insulin sensitivity and improving blood plasma lipid profile is also emphasized [38]. This is an important advantage due to the clear correlation between obesity and insulin resistance [41]. The energy density is defined as the amount of energy per specific portion of food. An example unit is calories per gram. Both the water content and the distribution of macronutrients in a product affect its final energy density value [42]. The vegetarian diet is rich in low energy density products, so that a meal composed of plant-based products will be both saturated and less calorific than a standard meal of similar volume. This is a very beneficial solution for people who fight against obesity. In addition, the introduction of low calorie density products into the menu can be more beneficial for weight loss than reducing meal size [39]. It has been proven that a low-fat plantbased diet is conducive to weight loss, even when the supply of ingested calories is not controlled and participants eat to their preferred level of satiety. One of the advantages of The whole food plant-based diet (WFPB) is the fact that it is well balanced, rich in microelements and helps to maintain proper blood sugar levels [43].

\subsection{Osteoporosis}

Osteoporosis is a systematic disorder of progressive decrease in bone mass, altered structure and diminished bone durability due to the metabolic processes occurring in the bone. Main clinical symptoms of osteoporosis are low-energy fractures - fractures occurring with a presence of energy, that wouldn't break a healthy bone. Adequate nutrition, appropriate calcium and vitamin D intake, regular menstrual cycles and a well-balanced exercise program of exercise are essential elements in achieving peak bone mass, which is a necessity for prevention of osteoporosis and maintenance of healthy bones [44].

To fully analyze the effect of vegetarian diet on any alteration in osteoporosis occurrence, and/or deterioration of existing disease, there is a need of focusing on potentially modifiable osteoporosis risk factors. Within this investigation, only risk factors linked with altered nutrition are taken into the consideration.

Vegetarian diet is most commonly associated with insufficient intake of exogenous vitamins and nutrients like: calcium, vitamin D, vitamin B-12, protein, $n-3(\Omega-3)$ fatty acids [44]. All the stated above have a crucial role in maintaining proper bone function. Although zinc intakes are not necessarily lower quantitatively, they are considerably less bioavailable in vegetarian diets, which suggests the need for even higher intakes to maintain adequate status [44]. 
As the vegetarian diet involves restriction in the intake meat and fish-derived products, that are most commonly associated with high abundance of calcium and vitamin D, like anchovies and sardines (or any other fish eaten with bones especially that are rich in calcium) and vitamin D sources as salmon, cod liver oil, and other fish products [45], there could be an assumption driven that vegetarians lack the source of those nutrients. Such exclusion is directly linked to decreased levels of these crucial for bone health nutrients, whereas decreased levels of both calcium and vitamin D can be, with very high probability, linked to the development of osteoporosis [46]. What is important to state, the vast majority of supplementation of vitamin D is based on fish-derived products, which means that plant-based supplementation is not easily accessible and much more expensive than this excluded in terms of vegetarian diet. That clearly can be one of the reasons for increased potential risk of osteoporosis occurrence in vegetarians. A 2009 meta-analysis of 9 studies found that vegetarians had 4\% lower Bone Mineral Density (BMD) than omnivores [44].

Despite this difference in BMD, some studies show that risk of fractures in vegetarians and nonvegetarians was not affected by diet alteration $[46,47]$. This observation needs to be taken into consideration, as even significant changes in examination of BMD has no value without clinical symptoms like fractures. It cannot be diminished, as it can lead to possible clinical symptoms in the future, nevertheless low-energy fractures should be the main criteria taken into consideration in assessment of the influence of vegetarianism on severity of osteoporosis.

\section{Summary and conclusions}

The impact of vegetarian diet on preventing the hypertension and hypertension itself is significant. Using this diet people have lower blood pressure what prevents them from blood flow based diseases. What's more this well-balanced diet helps people to weight loss what could contribute in fight against obesity all over the world. There is correlation between the diet and osteoporosis, Bone Mineral density is generally lower by vegetarian although clinical symptoms hasn't shown that these bones are weaker.

Vegetarian diet has a great impact on human body that's why everyone should take it in consideration to change diet. Although there is a need for a further research of this diet and it is impact on other civilization diseases, like heart failure or metabolic syndrome as well as some mineral and vitamin deficiencies.

\section{References}

1. Deals On Health. (2020, August 31). 20 Remarkable Vegetarian Statistics [The 2020 Serving]. Retrieved from https://dealsonhealth.net/blog/vegetarian-statistics/

2. Monica Dinu, Rosanna Abbate, Gian Franco Gensini, Alessandro Casini \& Francesco Sofi (2017) Vegetarian, vegan diets and multiple health outcomes: A systematic review with meta-analysis of observational studies, Critical Reviews in Food Science and Nutrition, 57:17, 3640-3649, DOI: $10.1080 / 10408398.2016 .1138447$

3. Skorek, P., Glibowski, P., \& Banach, K. (2019). Nutrition of vegetarians in Poland - a review of research. Roczniki Państwowego Zakładu Higieny, 217-223. doi:10.32394/rpzh.2019.0072

4. $2018 \mathrm{ESC} / \mathrm{ESH}$ Guidelines for the management of arterial hypertension. (2019). Journal of Hypertension, 37(1), 226. doi:10.1097/hjh.0000000000002017

5. $\quad$;. (n.d.). Worldwide trends in blood pressure from 1975 to 2015: A pooled analysis of 1479 population-based measurement studies with $19 \cdot 1$ million participants. Retrieved from https://pubmed.ncbi.nlm.nih.gov/27863813/

6. Mozaffarian, D., Benjamin, E. J., Go, A. S., Arnett, D. K., Blaha, M. J., Cushman, M., . . Turner, M. B. (2016). Heart Disease and Stroke Statistics-2016 Update. Circulation, 133(4).

doi:10.1161/cir.0000000000000350 
7. Redburn, K. (n.d.). Hypertension Globally. Retrieved from http://www.whleague.org/index.php/jstuff/hypertension-globally

8. Lim SS, Vos T, Flaxman AD, et al. A comparative risk assessment of burden of disease and injury attributable to 67 risk factors and risk factor clusters in 21 regions, 1990-2010: a systematic analysis for the Global Burden of Disease Study 2010. Lancet (London, England). 2012 Dec;380(9859):2224-2260. DOI: 10.1016/s0140-6736(12)61766-8.

9. Pugh, D., Gallacher, P.J. \& Dhaun, N. Management of Hypertension in Chronic Kidney Disease. Drugs 79, 365-379 (2019). https://doi.org/10.1007/s40265-019-1064-1

10. Cohen DL, Townsend RR. Hypertension and kidney disease: what do the data really show?. Curr Hypertens Rep. 2012;14(5):462-467. doi:10.1007/s11906-012-0285-4

11. Ettehad D, Emdin CA, Kiran A, et al. Blood pressure lowering for prevention of cardiovascular disease and death: a systematic review and meta-analysis. Lancet. 2016;387(10022):957-967. doi:10.1016/S0140-6736(15)01225-8

12. Thomopoulos C, Parati G, Zanchetti A. Effects of blood pressure lowering on outcome incidence in hypertension. 1. Overview, meta-analyses, and meta-regression analyses of randomized trials. J Hypertens. 2014;32(12):2285-2295. doi:10.1097/HJH.0000000000000378

13. Spencer, E., Appleby, P., Davey, G. et al. Diet and body mass index in 38000 EPIC-Oxford meateaters, fish-eaters, vegetarians and vegans. Int J Obes 27, 728-734 (2003).

https://doi.org/10.1038/sj.ijo.0802300

14. Rosell, M., Appleby, P., Spencer, E. et al. Weight gain over 5 years in 21966 meat-eating, fisheating, vegetarian, and vegan men and women in EPIC-Oxford. Int J Obes 30, 1389-1396 (2006).

https://doi.org/10.1038/sj.ijo.0803305

15. Cade, J., Burley, V., \& Greenwood, D. (2004). The UK Women's Cohort Study: Comparison of vegetarians, fish-eaters and meat-eaters. Public Health Nutrition, 7(7), 871-878. doi:10.1079/PHN2004620

16. Matsumoto S, Beeson WL, Shavlik DJ, et al. Association between vegetarian diets and cardiovascular risk factors in non-Hispanic white participants of the Adventist Health Study-2. J Nutr Sci. 2019;8:e6. Published 2019 Feb 21. doi:10.1017/jns.2019.1

17. Dandona P, Mohanty $\mathrm{P}$, Ghanim H, et al. The suppressive effect of dietary restriction and weight loss in the obese on the generation of reactive oxygen species by leukocytes, lipid peroxidation, and protein carbonylation. J Clin Endocrinol Metab. 2001;86(1):355-362. doi:10.1210/jcem.86.1.7150

18. Pearce KL, Hill A, Tremellen KP. Obesity related metabolic endotoxemia is associated with oxidative stress and impaired sperm DNA integrity. Basic Clin Androl. 2019;29:6. Published 2019 May 13. doi:10.1186/s12610-019-0087-5

19. Montezano AC, Touyz RM. Oxidative stress, Noxs, and hypertension: experimental evidence and clinical controversies [published correction appears in Ann Med. 2012 Dec;44(8):854-8]. Ann Med. 2012;44 Suppl 1:S2-S16. doi:10.3109/07853890.2011.653393

20. Rodrigo R, González J, Paoletto F. The role of oxidative stress in the pathophysiology of hypertension. Hypertens Res. 2011;34(4):431-440. doi:10.1038/hr.2010.264

21. Zhou, M., Wang, A. \& Yu, H. Link between insulin resistance and hypertension: What is the evidence from evolutionary biology?. Diabetol Metab Syndr 6, 12 (2014). https://doi.org/10.1186/17585996-6-12 
22. Ascherio, A., Rimm, E. B., Giovannucci, E. L., Colditz, G. A., Rosner, B., Willett, W. C., ... Stampfer, M. J. (1992). A prospective study of nutritional factors and hypertension among US men. Circulation, 86(5), 1475-1484. doi:10.1161/01.cir.86.5.1475

23. Lee KW, Loh HC, Ching SM, Devaraj NK, Hoo FK. Effects of Vegetarian Diets on Blood Pressure Lowering: A Systematic Review with Meta-Analysis and Trial Sequential Analysis. Nutrients. 2020 May;12(6). DOI: 10.3390/nu12061604.

24. Alexander S, Ostfeld RJ, Allen K, Williams KA. A plant-based diet and hypertension. Journal of Geriatric Cardiology : JGC. 2017 May;14(5):327-330. DOI: 10.11909/j.issn.1671-5411.2017.05.014.

25. Margetts BM, Beilin LJ, Vandongen R, Armstrong BK. Vegetarian diet in mild hypertension: a randomised controlled trial. Br Med J (Clin Res Ed). 1986;293(6560):1468-1471.

doi:10.1136/bmj.293.6560.1468

26. Appel, L. J., Moore, T. J., Obarzanek, E., Vollmer, W. M., Svetkey, L. P., Sacks, F. M., ... Harsha, D. W. (1997). A Clinical Trial of the Effects of Dietary Patterns on Blood Pressure. New England Journal of Medicine, 336(16), 1117-1124. doi:10.1056/nejm199704173361601

27. Kuo, K., Liu, H., \& Liu, J. (2018). Vegetarian diet and blood pressure in a hospital-base study. Tzu Chi Medical Journal, 30(3), 176. doi:10.4103/tcmj.tcmj_91_17

28. Najjar, R. S., Moore, C. E., \& Montgomery, B. D. (2018). A defined, plant-based diet utilized in an outpatient cardiovascular clinic effectively treats hypercholesterolemia and hypertension and reduces medications. Clinical Cardiology, 41(3), 307-313. doi:10.1002/clc.22863

29. Shridhar, K., Dhillon, P. K., Bowen, L., Kinra, S., Bharathi, A. V., Prabhakaran, D., . . Ebrahim, S. (2014). The Association between a Vegetarian Diet and Cardiovascular Disease (CVD) Risk Factors in India: The Indian Migration Study. PLoS ONE, 9(10). doi:10.1371/journal.pone.0110586

30. Weng, L., Steffen, L., Szklo, M., Nettleton, J., Chambless, L., \& Folsom, A. (2013). A Diet Pattern with More Dairy and Nuts, but Less Meat Is Related to Lower Risk of Developing Hypertension in MiddleAged Adults: The Atherosclerosis Risk in Communities (ARIC) Study. Nutrients, 5(5), 1719-1733. doi:10.3390/nu5051719

31. Tsigos C, Hainer V, Basdevant A, et al. Management of obesity in adults: European clinical practice guidelines. Obes Facts. 2008;1(2):106-116. doi:10.1159/000126822

32. https://www.who.int/news-room/fact-sheets/detail/obesity-and-overweight, Accessed: 12 Sept 2020.

33. Karczewski J, Begier-Krasińska B, Staszewski R, Popławska E, Gulczynska-Elhadi K, Dobrowolska A. Obesity and the Risk of Gastrointestinal Cancers. Dig Dis Sci. 2019;64(10):2740-2749. doi:10.1007/s10620-019-05603-9

33. Saitta C, Pollicino T, Raimondo G. Obesity and liver cancer. Ann Hepatol. 2019;18(6):810-815. doi:10.1016/j.aohep.2019.07.004

34. Medawar E, Huhn S, Villringer A, Veronica Witte A. The effects of plant-based diets on the body and the brain: a systematic review. Transl Psychiatry. 2019;9(1):226. Published 2019 Sep 12. doi:10.1038/s41398-019-0552-0

35. Sterling SR, Bowen SA. The Potential for Plant-Based Diets to Promote Health Among Blacks Living in the United States. Nutrients. 2019;11(12):2915. Published 2019 Dec 2. doi:10.3390/nu11122915

36. Gogga P, Śliwińska A, Aleksandrowicz-Wrona E, Małgorzewicz S. Association between different types of plant-based diets and leptin levels in healthy volunteers. Acta Biochim Pol. 2019;66(1):77-82.

doi:10.18388/abp.2018_2725 
37. Pilis W, Stec K, Zych M, Pilis A. Health benefits and risk associated with adopting a vegetarian diet. Rocz Panstw Zakl Hig. 2014;65(1):9-14

38. Najjar RS, Feresin RG. Plant-Based Diets in the Reduction of Body Fat: Physiological Effects and Biochemical Insights. Nutrients. 2019;11(11):2712. Published 2019 Nov 8. doi:10.3390/nu11112712

39. Tuso PJ, Ismail MH, Ha BP, Bartolotto C. Nutritional update for physicians: plant-based diets. Perm J. 2013;17(2):61-66. doi:10.7812/TPP/12-085

40. Hardy OT, Czech MP, Corvera S. What causes the insulin resistance underlying obesity?. Curr Opin Endocrinol Diabetes Obes. 2012;19(2):81-87. doi:10.1097/MED.0b013e3283514e13

41. Rolls BJ. Dietary energy density: Applying behavioural science to weight management. Nutr Bull. 2017;42(3):246-253. doi:10.1111/nbu.12280

42. Wright N, Wilson L, Smith M, Duncan B, McHugh P. The BROAD study: A randomised controlled trial using a whole food plant-based diet in the community for obesity, ischaemic heart disease or diabetes. Nutr Diabetes. 2017;7(3):e256. Published 2017 Mar 20. doi:10.1038/nutd.2017.3

43. Tucker KL. Vegetarian diets and bone status. Am J Clin Nutr. 2014;100 Suppl 1:329S-35S. doi:10.3945/ajen.113.071621

44. Bischoff-Ferrari HA, Willett WC, Wong JB, Giovannucci E, Dietrich T, Dawson-Hughes B.

Fracture prevention with vitamin D supplementation: a meta-analysis of randomized controlled trials. JAMA. 2005;293(18):2257-2264. doi:10.1001/jama.293.18.2257

45. Cranney A, Horsley T, O'Donnell S, et al. Effectiveness and safety of vitamin D in relation to bone health. Evid Rep Technol Assess (Full Rep). 2007;(158):1-235.

46. Appleby P, Roddam A, Allen N, Key T. Comparative fracture risk in vegetarians and nonvegetarians in EPIC-Oxford. Eur J Clin Nutr. 2007;61:1400â€"1406.

47. Ho-Pham LT, Vu BQ, Lai TQ, et al. Vegetarianism, bone loss, fracture and vitamin D: a longitudinal study in Asian vegans and non-vegans. Eur J Clin Nutr. 2012;66:75â€“"82. 